\section{Marketing Case Study: How to beat the litterbug Part II}

\author{
Hugh G. Clarke
}

Personnel Manager, Lewis Stores, Cape Town, 68 Dean Street, Newlands 7700, RSA

Received 16 March 1980

Ever since the South African Journal of Business Management published my article 'How to beat the Litterbug' (Vol. 10, No. 4, 1979) I have been inundated with requests seeking more information on this problem.

You will recollect that my last article was, ostensibly, concerned with the siting and design of the litterbin and strategies required to ensure that refuse ended up where it should - in the bin. In the process, I put forward a number of principles whose applications were shown to be of relevance to the marketing person.

The four 'behavioural science' principles discussed in that article were:

Principle 1: The further from the source, the less likelihood of the message getting through, whether it is to a litterbin or to the consumer. (Zipf)'.

Principle 2: People will tend to expend the least energy possible in performing a task (Zipf) ${ }^{2}$.

Principle 3: The amount of information man is instantly able to receive, process and remember is limited to plus/minus seven items of information. (Miller) ${ }^{3}$.

Principle 4: A few items, in terms of numbers, will always account for a large proportion in terms of effort (Pareto) ${ }^{4}$.

From the marketing point of view, Principle 1 was related to store location, display material and incentive schemes; Principle 2 to product design, advertising readership, customer service, shop parking and direct mail; Principle 3 to brand name recall, advertising slogans, selling of product benefits and market research; Principle 4 to inventory strategy, sales skills and customer profiles.

The erroneous impression might have been created that 'that was it', no more could be said. Astonishing, isn't it, how poorly the behavioural scientist sells himself? It is as though his contributions to business management were of no real significance - or at least of lesser value than that of the 'pure scientist'. Indeed, 1 have just come across a recruitment advertisement (Sunday Times, February 17 th) in which applications for research scientists are called for - Biologist, Climatologist, Geologist, Electronics Engineer, Chemist, Chemical Engineer, Physicist - but not one request for a 'behavioural scientist'. What a poor reflection on our status!

Why it is that the behavioural scientist is ignored, is a source of wonder. The influence of our automated, com- puterized, technocratic environment? But, just to illustrate the point, I have before me Martin K. Starr's Production Management, systems and synthesis (Prentice-Hall, 1972). In this book Starr discusses, inter alia, Frank Gilbreth's pioneering contribution to time and motion study. We read all about therblig's and Motion-Time-Analysis (MTA), etc., but not a mention about Rudolf Laban. Indeed, many readers will ask: who was Rudolf Laban?

In fact he was one of England's leading choreographers and dancers who applied the artistic principles of body movement (grace, flow, fluidity) to work effort and by doing so, helped to increase British labour productivity during the second world war'. He showed, for example, that while the so-called 'best' way to lift an object in terms of directness of movement is a short 'snatch and jerk' which optimizes distance travelled, this is not the most effortless method as it places considerable stress on, and fatigue in, the lifter. Rather, a slightly swaying motion with a gliding action is more effective...

But I digress. The problem you will recollect is 'how to beat the litterbug'. Now one simple solution which we did not mention is for government officials and other legislative bodies to make littering an offence. We need a concerted attack on the litterbug mustering all our forces - governmental, social, civic, and individual. This has already been very successfully done in some countries where littering is almost unheard of (e.g. Switzerland). In other words, to achieve our objectives we must put some 'beef' into our anti-litter campaign.

Principle 5: The more energy you put into a project, the more you get out of it. The principle of energy release. This applies to just about everything. A company that expends its energy resources - capital, manpower, machinery - in a goal-directed effort, will achieve results in proportion to the amount of energy it expends. (Subject, of course, to the constraints of two other behavioural laws - the law of diminishing returns, and the law of countervailing power.)

In terms of our anti-litter campaign, our payoff matrix can be simply related to cost and cost ef fectiveness. What is the cost, in terms of health, environmental damage, and the like, of scarring the landscape? How much energy should we expend to get it right?

As far as the marketer is concerned, this principle implies

- the more you spend on promoting your product;

- the greater the number of hours you spend training your sales personnel;

- the higher the incidence of customer calls, etc. the better the sales results. So there's nothing new here.

Well, yes, there is, in a way. Because as soon as you start expending energy, the question of methodology becomes relevant, for example 'How are you going to design the ideal litterbin?' or 'How are you going to gain market share?' In seeking out the answer to this question yet another principle comes into play.

Principle 6: The two opposing forces of complexity and simplicity will always tend towards each other. The principle of central tendency: See Fig. 1. 
80

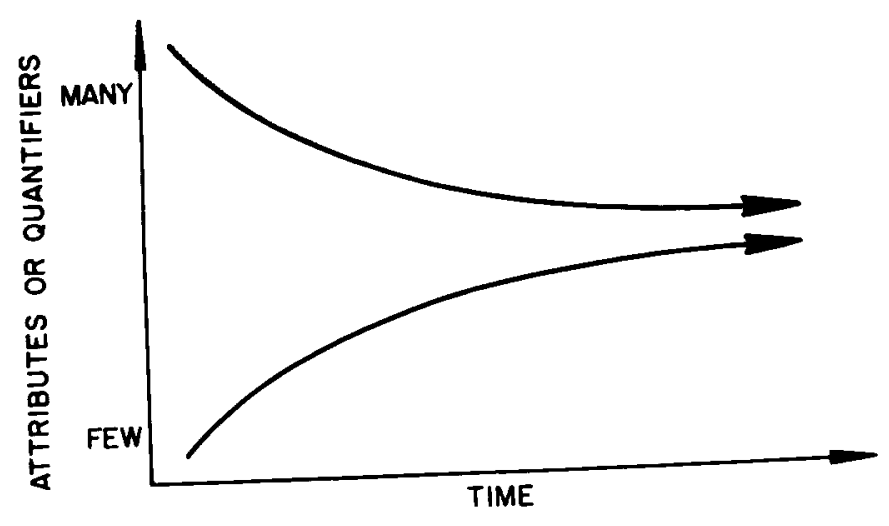

Fig. 1. The principle of central tendency

There are simply dozens of examples which validate this principle. For example:

\begin{tabular}{|c|c|c|}
\hline Application & Complexity & Simplicity \\
\hline Production & $\begin{array}{l}\text { Short run batch } \\
\text { production }\end{array}$ & $\begin{array}{l}\text { Long run con- } \\
\text { tinuous production }\end{array}$ \\
\hline Plant size & Inefficiencies of size & Economies of scale \\
\hline Inventory & $\begin{array}{l}\text { Wide variety of } \\
\text { products }\end{array}$ & $\begin{array}{l}\text { Selected range } \\
\text { stocked in depth }\end{array}$ \\
\hline Product design & Multi-purpose tool & Single purpose tool \\
\hline Work situation & Generalist & Specialization \\
\hline
\end{tabular}

Of course, the pundits may argue that there are shades of difference here that I should have brought out. Okay, I'll buy that. But you can spend an awfully long time hunting the end of the rainbow.

So, let's get back to designing our litterbin. According to our principle it should be not too large . . . and not too small (obvious enough!), round in shape for structural strength and to eliminate sharp corners, with two handles for easy lifting, and made of reasonably lightweight material - perhaps heavy duty rubber or plastic to cut down the noise it makes when being dropped.

Because this design is simple, it violates principle six; so the tendency, in behavioural terms, is to complexity to add functions and uses. Doubtless you have seen those refuse bins which are used for advertising . . . and colourful they are; or shredder attachments; or at a much more complex level, refuse removal lorries which perform numerous functions at once.

From a marketing point of view, this principle has considerable significance. Make your product, in terms of design and appeal of 'limited complexity'. For example, suppose you sell home gadgets. Don't make a bottle opener (one feature), but a bottle opener cum corkscrew (two features). Perhaps you will increase the versatility of your gadget even further . . . but not to the extent where you have every conceivable object in the world hinged together into an incredible monolithic lump like those huge Swiss knives with about twenty functions. They may sell (as a novelty), but they are not used.

Product design strategy is an important consideration in trying to win over the consumer. You increase customer resistance by too much functional versatility in one unit - bottle opener/corkscrew/knife/screwdriver/ pick, etc. A better approach would be to create a tool which is specialized in itself, yet allows combination, for example a power tool kit with various attachments, or a food mixer or a vacuum cleaner with attachments. If you generalize the principal appeal, you weaken it.

The Russian psychologist, Pavlov, first noted this tendency - a generalized stimulus leads to a lower response. For example, judge your own reaction to the word 'Kellogg's'. Kellogg's what? Kellogg's cornflakes is acceptable, Kellogg's All Bran and Rice Crispies less so. If Kelloggs diversified their product range completely for example Kellogg's chewing gum, Kellogg's brandy, Kellogg's toothpaste, etc., the impact of the brand name 'Kellogg's' would be very limited.

But back to the litterbin. Have you noticed that, over the years, its shape hasn't changed much? Ever wondered why? Here's a possible answer.

Principle 7: Efficient organisms are less likely to need to alter their forms and functions or to become extinct. The law of recapitulation of biology.

So it looks as though our litterbin is here to stay. From a marketing point of view this principle suggests you can increase the length of the product life cycle if you design your product efficiently so that it doesn't require too much modification. Examples: a knife, a fork, a lightbulb, perhaps even the VW Beetle.

Back to littering. In terms of a means-end chain it seems we can't do too much about the end product - the design of the litterbin. So we have to 'get at' the source, the litterbug. How do we modify his or her behaviour and how socially entrenched is the problem? Principle 8 suggests an answer.

Principle 8: The longer a given norm of conduct has existed, the ionger it is likely to exist in the face of continuing changes.

This principle is almost the death-knell of social reform. Take cigarette smoking, for instance. Despite the overwhelming evidence against smoking as a health hazard, the smoker either ignores, minimizes or rejects the warnings. So while a propaganda campaign and legislation aimed at the litterbug may work, as soon as we cease our efforts, the litter increases. It's like hoping motorists will continue to drive slowly once the speed limit is raised. Or, from a marketing point of view, like stopping your advertising campaign for a new product and still hoping to get results.

So how do we beat the litterbug? Changing the design and shape of the bin won't help. A strong advertising campaign coupled with enforced legislation may. Perhaps though, most of all, we have to marshall those forces within society, to utilize group dynamics to get concentrated action going against the litterbug. And how to do that as a marketer? Well, for a start, call in your nearest and best behavioural scientist!

\section{References}

1. ZIPF, G.K. Some determinants of the circulation of information. 1946. Am. J. Psychol., 59: $401-421$.

2. ZIPF, G.K. Human behaviour and the Principle of Least Effort. 1949. Addison-Wesley, Cambridge, Massachusetts.

3. MILLER, GEORGE A. The psychology of communication. 1967. Penguin, Hammondsworth, Middlesex.

4. PARETO, W. Cours d'Economic politique. In: Stock control: The profit booster. (ed.) Van Wijk, L. 1979. Foresight, pp 18-25.

5. LABAN, R. \& LAWRENCE, F.C. Effort. 1947. MacDonald \& Evans, London. 